\title{
Mosaic trisomy 7
}

INSERM

\section{Source}

INSERM. (1999). Orphanet: an online rare disease and orphan drug data base. Mosaic

trisomy 7. ORPHA:1747

Mosaic trisomy 7 is a rare chromosomal anomaly syndrome, with a highly variable phenotype, mostly characterized by blaschkolinear skin pigmentary dysplasia, body asymmetry, enamel dysplasia, and developmental and growth delay. Intellectual disability, facial dysmorphism (e.g. frontal bossing, abnormal palpebral fissures, strabismus, abnormally shaped ears, and microg nathia), and genital anomalies (e.g. undescended testes) have also been observed. It has been reported to be associated with maternal uniparental disomy of chromosome 7, resulting in a Silver-Russell syndrome phenotype. Cases with no associated malformations have also been reported. 